\title{
Blocking granule-mediated death by primary human NK cells requires both protection of mitochondria and inhibition of caspase activity
}

\author{
KA Sedelies ${ }^{1}$, A Ciccone ${ }^{1}$, CJP Clarke ${ }^{2}$, J Oliaro ${ }^{3}$, VR Sutton ${ }^{1}$, FL Scott ${ }^{4}$, J Silke ${ }^{5}$, 0 Susanto $^{1}$, DR Green ${ }^{6}$, RW Johnstone ${ }^{2}$, PI Bird ${ }^{7}$, \\ JA Trapani ${ }^{1,8,9}$ and NJ Waterhouse ${ }^{*, 1,8}$
}

\begin{abstract}
Human GraB (hGraB) preferentially induces apoptosis via Bcl-2-regulated mitochondrial damage but can also directly cleave caspases and caspase substrates in cell-free systems. How hGraB kills cells when it is delivered by cytotoxic lymphocytes (CL) and the contribution of hGraB to CL-induced death is still not clear. We show that primary human natural killer (hNK) cells, which specifically used $\mathrm{hGraB}$ to induce target cell death, were able to induce apoptosis of cells whose mitochondria were protected by Bcl-2. Purified hGraB also induced apoptosis of Bcl-2-overexpressing targets but only when delivered at 5- to 10-fold the concentration required to kill cells expressing endogenous $\mathrm{Bcl}-2$. Caspases were critical in this process as inhibition of caspase activity permitted clonogenic survival of $\mathrm{Bcl}-2$-overexpressing cells treated with $\mathrm{hGraB}$ or $\mathrm{hNK}$ cells but did not protect cells that only expressed endogenous $\mathrm{Bcl}-2$. Our data therefore show that $\mathrm{hGraB}$ triggers caspase activation via mitochondria-dependent and mitochondria-independent mechanisms that are activated in a hierarchical manner, and that the combined effects of Bcl-2 and direct caspase inhibition can block cell death induced by hGraB and primary hNK cells.
\end{abstract}

Cell Death and Differentiation (2008) 15, 708-717; doi:10.1038/sj.cdd.4402300; published online 18 January 2008

Cytotoxic lymphocytes (CL) kill their targets by granule exocytosis, a process involving perforin-mediated delivery of granzymes to the target cell. Various purified granzymes have been shown to kill cultured cells when delivered by perforin or perforin substitutes, but the mechanism by which they induce death when they are delivered by intact $C L$ and their individual contributions to the totality of $\mathrm{CL}$-induced cell death remains unresolved. The current study sought to understand how human GraB (hGraB) triggers cell death when it is delivered by intact $C L$.

Various studies have proposed that GraB induces apoptosis by (i) directly cleaving and activating caspases, ${ }^{1-3}$ (ii) triggering release of caspase-activating proteins from mitochondria $^{4-8}$ or (iii) cleaving various caspase substrates or novel noncaspase substrates. ${ }^{9-11}$ GraB can directly cleave and activate several caspases when added directly to target cell lysates. ${ }^{1-3}$ Activation of caspase-3 occurs by a two-step process in which GraB directly cleaves pro-caspase-3 between the large and small subunits to generate a $20 \mathrm{kDa}$ fragment that undergoes autoprocessing to generate the fully

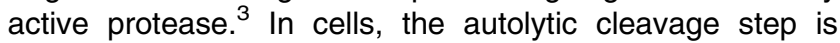
blocked by inhibitor of apoptosis proteins (IAPs) suggesting that GraB-mediated cleavage of caspases is not sufficient to induce apoptosis. ${ }^{7,12}$ Further, inhibition of caspase activity per se did not permit clonogenic survival of GraB-treated cells, suggesting that another substrate must play a critical role in GraB-induced death. ${ }^{8}$ GraB also cleaves Bid and Mcl-1, members of the Bcl-2 family that regulate mitochondrial outer membrane permeabilization (MOMP) and subsequent release of soluble proteins (including cytochrome $c$ (cyt $c$ ) and second mitochondrial activator of caspases (SMAC/Diablo)) from the mitochondrial intermembrane space. ${ }^{4-8}$ Upon release, cyt $c$ triggers formation of an apoptosome complex that activates caspase- 9 , and SMAC facilitates activation of caspase-3 by deregulating IAPs. ${ }^{7,12,13}$

Several studies predict that MOMP plays a critical role in GraB-induced apoptosis, ${ }^{6-8,12,14-16}$ while others predict that mitochondria merely amplify prior activation of caspases. ${ }^{17,18}$ One potential resolution to this important discrepancy is that mouse and hGraB, used in different studies, cleave different substrates. ${ }^{19-21}$ Both human and mouse GraB efficiently cleaved caspase-3 and caspase-7 in cell-free systems but only hGraB efficiently cleaved Bid. ${ }^{19-21}$ The mitochondrial pathway may therefore be critical during hGraB-induced

\footnotetext{
${ }^{1}$ Cancer Cell Death Laboratory, Cancer Immunology Program, Peter MacCallum Cancer Centre, Locked Bag 1, A'Beckett Street, Melbourne, Victoria 8006, Australia; ${ }^{2}$ Gene Regulation Laboratory, Cancer Immunology Program, Peter MacCallum Cancer Centre, Locked Bag 1, A'Beckett Street, Melbourne, Victoria 8006, Australia; ${ }^{3}$ Cell Signaling Laboratory, Cancer Immunology Program, Peter MacCallum Cancer Centre, Locked Bag 1, A'Beckett Street, Melbourne, Victoria 8006, Australia; ${ }^{4}$ Program in Apoptosis and Cell Death Research, Burnham Institute for Medical Research, La Jolla, CA 92037, USA; ${ }^{5}$ Department of Biochemistry, LaTrobe University, Kingsbury Drive, Bundoora, Melbourne, Victoria 3086, Australia; ${ }^{6}$ Department of Immunology, St Judes Childrens Research Hospital, 332 N. Lauderdale, Memphis, TN 38105, USA; ${ }^{7}$ Department of Biochemistry and Molecular Biology, Monash University, Clayton 3600, Australia; ${ }^{8}$ Department of Pathology, University of Melbourne, Parkville, Melbourne, Victoria 3052, Australia and ${ }^{9}$ Department of Microbiology and Immunology, University of Melbourne, Parkville, Melbourne, Victoria 3052, Australia ${ }^{*}$ Corresponding author: NJ Waterhouse, Cancer Cell Death Laboratory, Cancer Immunology Program, Peter MacCallum Cancer Centre, Locked Bag 1, A'Beckett Street, Melbourne, Victoria 8006, Australia. Tel: + 6139656 3725; Fax: + 6139656 1411; E-mail: nigel.waterhouse@ @etermac.org Keywords: granzyme; apoptosis; Bcl-2; lymphocyte; mitochondria

Abbreviations: $\mathrm{CL}$, cytotoxic lymphocytes; CTL, cytotoxic T lymphocytes; cyt $c$, cytochrome $c$; GraB, granzyme B; NK, natural killer cells; PI, propidium iodide; PS, phosphatidylserine; SMAC, second mitochondrial activator of caspases

Received 06.8.07; revised 05.11.07; accepted 05.11.07; Edited by SJ Martin; published online 18.1.08
} 
apoptosis but less important in mice. Consistent with this, cells that were deficient in Bid or overexpressed $\mathrm{Bcl}-2$ survived and proliferated following treatment with $\mathrm{hGraB},{ }^{8,22}$ but $\mathrm{Bid}^{-/-}$ cells did not survive following treatment with mGraB. ${ }^{18}$ Conversely, cells treated with $\mathrm{mGraB}$ in the presence of caspase inhibitors survived and continued to proliferate but cells exposed to hGraB in the presence of caspase inhibitors did not. ${ }^{8,20} \mathrm{GraB}$ can also process nearly 30 other proteins, ${ }^{9-11}$ several of which are also targeted by caspases. It is possible that direct cleavage of these proteins by GraB might result in apoptosis without the need for MOMP or caspase activation. The relative importance of these pathways in GraB-induced apoptosis is still vigorously debated and the relative contribution of these pathways to CL-induced cell death is not clear.

$\mathrm{Bcl}-2$ is a critical regulator of the mitochondria-dependent pathway to apoptosis. Overexpression of $\mathrm{Bcl}-2$ blocks apoptosis induced by various stimuli that exclusively activate the mitochondria-dependent pathway to apoptosis and renders cells resistant to many cytotoxic drugs. Importantly, overexpression of $\mathrm{Bcl}-2$ also blocks hGraB-induced MOMP but does not block CL-induced death of target cells following granule exocytosis. $6,8,23,24$ To investigate the contribution of hGraB-mediated MOMP to human CL-induced death, we wished to determine how human CL kill cells that overexpress Bcl-2.

We found that human natural killer (hNK) cells killed HeLa$\mathrm{Bcl}-2$ cells by apoptosis and this process was blocked by compound 20, a membrane-permeable inhibitor of GraB. HeLa-Bcl-2 cells were resistant to lower concentrations of hGraB (12.5 nM, as we have previously reported), but higher concentrations of hGraB $(125 \mathrm{nM})$ were able to overcome Bcl-2's protection suggesting that hGraB can trigger two separate pathways to cell death: a mitochondriadependent pathway that is very sensitive to hGraB and a second, mitochondria-independent, pathway that requires higher concentrations of hGraB. hNK cells were delivered between 600 and $1200 \mathrm{nM}$ hGraB to HeLa-Bcl-2 cells, which would be sufficient for hGraB to activate both pathways. Finally, inhibition of both mitochondrial damage and caspase activity, but not either alone, maintained the clonogenic survival of HeLa cells treated with hNK cells or high concentrations of hGraB demonstrating the critical role of both hGraB-mediated MOMP and MOMP-independent activation of caspases in NK-induced death. Our data therefore (1) demonstrates the importance of the Bcl-2-regulated mitochondrial pathway to GraB-induced apoptosis while elucidating a bona fide role for alternative pathways to caspase activation, (2) resolves apparent differences between studies which predict that GraB induces MOMP-dependent apoptosis by cleaving and activating Bid and studies which predict that GraB triggers MOMPindependent activation of caspases, (3) demonstrates the ability of XIAP to regulate NK-induced apoptosis and (4) functionally demonstrates the importance of these pathways during hNK-induced death.

\section{Results}

NK cells induce apoptosis of HeLa-Bcl-2. Human NK cells isolated from peripheral blood and activated with low concentrations of rIL-2 (25U) for 2 days, killed HeLa-Bcl-2 cells at low effector-to-target ratios (2:1; Figure 1a). This death was blocked by EGTA, confirming involvement of the granule exocytosis pathway in this process. Bcl-2 was functional in these cells as their resistance to UV-induced apoptosis was reversed by the Bcl-2 antagonist ABT-737 (Supplementary Figure 1). We observed that hNK cells killed HeLa-Bcl-2 cells by two morphologically distinct processes (Supplementary movie 1). The first involved rounding/
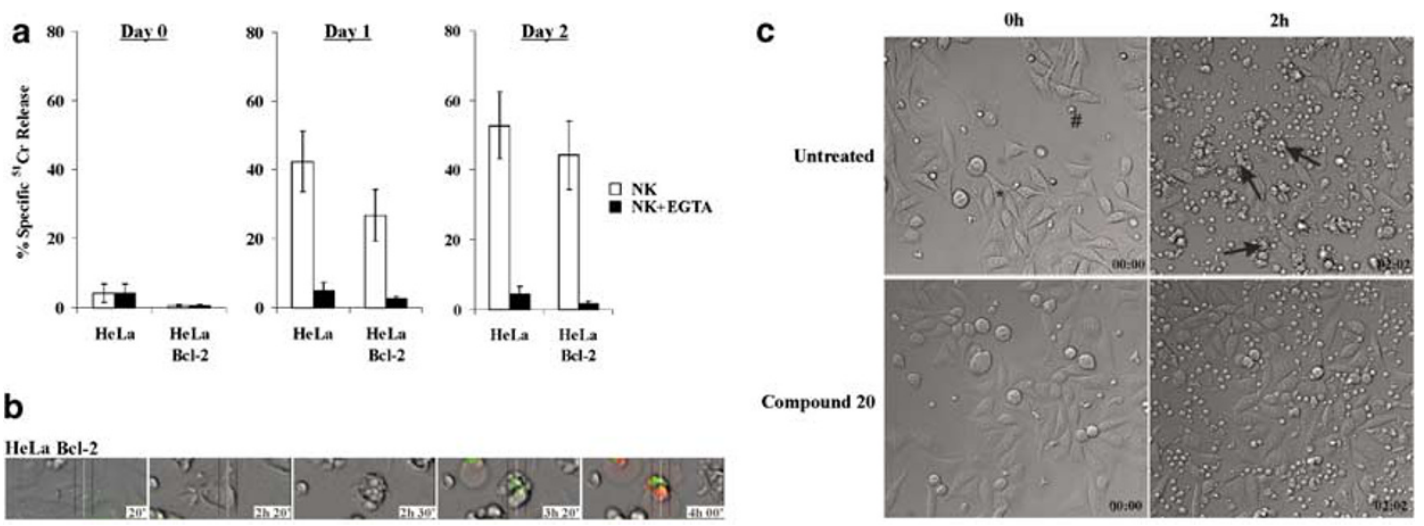

Figure 1 Natural killer cells kill HeLa-Bcl-2 by apoptosis. (a) NK cells isolated from peripheral blood and incubated with 25U IL-2 for 0, 1 or 2 days were added to HeLa cells and HeLa-Bcl-2 cells in the presence or absence of EGTA (4 mM). Cell death was assayed by release of ${ }^{51} \mathrm{Cr}$ that had been preloaded into the target cells (data represent average of independent experiments \pm S.E.M., $n=3$ for day $0, n=10$ for day 1 and $n=6$ for day 2). (b) HeLa-Bcl-2 cells were treated with NK cells that had been cultured in $25 \mathrm{U} \mathrm{IL-2}$ for 2 days and followed by time-lapse microscopy. Images of morphology (gray), annexin V-FITC (green) and propidium iodide (red) were obtained every 5 min and are presented as overlaid images. Representative fields of one cell; adherent $(20 \mathrm{~min})$ rounding $(2 \mathrm{~h} 20 \mathrm{~min})$, blebbing $(2 \mathrm{~h} 30 \mathrm{~min})$, annexin V + ve/ $/ \mathrm{PI}-\mathrm{ve}(3 \mathrm{~h} 20 \mathrm{~min})$ and annexin $\mathrm{V}+\mathrm{ve} / \mathrm{PI}+\mathrm{ve}(4 \mathrm{~h} \mathrm{~min}$ ) are shown. A movie of this cell and graphs of a line scan (indicated by the white line) showing the maximum intensity of morphology (blue), annexin V (green) and propidium iodide (red) is shown in Supplementary movie 3. (c) HeLa-Bcl-2 cells were treated with NK cells for $2 \mathrm{~h}$ in the presence or absence of compound $20(10 \mu \mathrm{M})$ and followed by time-lapse microscopy. DIC images taken immediately after NK cells were added (only a few NK that have landed in the field of view are visible) and after $2 \mathrm{~h}$ are presented. The large flat cells (*) are HeLa-Bcl-2 cells and the small round cells (\#) are NK cells. Arrows indicate apoptotic cells. A time-lapse movie from this experiment is presented as Supplementary movie 6 
blebbing of the plasma membrane similar to apoptotic cell death and the second involved swelling of the plasma membrane while the target cell remained flat, reminiscent of perforin-induced lysis (Supplementary movie 2). The relative proportion of each type of death varied between patient samples; however, the nonlytic death was always far more prevalent ( $>90 \%$ of deaths) when the NK cells had been cultured for less than 2 days. In contrast, lytic death was more evident when the NK cells had been cultured for longer. Previous studies have been reported using NK cells stimulated with $1000 \mathrm{U} / \mathrm{ml}$ of IL-2 for several days, however in our hands, these cells primarily killed HeLa-Bcl-2 cells by lysis (not shown). We wished to determine how NK cells killed by the nonlytic form of cell death and therefore used NK cells stimulated with $25 \mathrm{U}$ rIL-2 for 2 days at an effector-totarget ratio of $2: 1$.

Morphology alone is insufficient to distinguish between apoptosis and some alternate forms of cell death; ${ }^{25}$ however, apoptosis characteristically results in the exposure of phosphatidylserine (PS) on the outside of the cell before loss of plasma membrane integrity. We found that NK cells killed HeLa-Bcl-2 cells by apoptosis as the target cells rounded up, blebbed and PS became exposed on the outside of the plasma membrane before loss of its integrity (Figure 1b). We also observed this sequence of events when HeLa cells were treated with TRAIL, hGraB (Supplementary movies 4 and 5) or UV, which are known to induce apoptosis. Further, we found that NK cells killed $44 \%$ (S.E.M. $=3 \%, n=3$ ) HeLa-Bcl-2 cells in the absence of compound 20, a specific inhibitor of $\mathrm{GraB},{ }^{26}$ but killed only $6 \%$ (S.E.M. $=2 \%, n=3$ ) HeLa-Bcl-2 cells in the presence of compound 20 , indicating that NK-induced apoptosis of HeLa-Bcl-2 was mediated by hGraB (Figure 1c). In this model, death of $\mathrm{Bcl}-2$-overexpressing cells in response to intact hNK was dependent on hGraB and did not involve direct lysis by perforin.

High concentrations of hGraB induce caspase-dependent apoptosis of HeLa-Bcl-2. Several groups, including our own, have reported that Bcl-2-overexpressing cells were resistant to $\mathrm{hGraB}$-induced apoptosis, ${ }^{5,6,8}$ but in some instances, this resistance was only partial. ${ }^{6}$ We hypothesized that hNK cells may deliver sufficiently high concentrations of $\mathrm{hGraB}$ to circumvent the protection afforded by Bcl-2. We found that concentrations of hGraB in the low nanomolar range $(<30 \mathrm{nM})$ killed HeLa cells more efficiently than $\mathrm{HeLa}-\mathrm{Bcl}-2$, but higher concentrations ( $>125 \mathrm{nM}$ ) efficiently killed both HeLa and HeLa-Bcl-2 cells (Figure 2a). We observed similar results using Jurkat-Bcl-2, 143B-Bcl-2 and FDC-P1-Bcl-2 cells (not shown). Time-lapse microscopy revealed that the sequence of events during hGraB-induced death of HeLa-Bcl-2 cells (rounding/blebbing followed by annexin $\mathrm{V}$ binding, followed by loss of plasma membrane integrity) was indistinguishable from NK-induced apoptosis (Figure 2b). These data show that hGraB can induce apoptosis in HeLa-Bcl-2 cells only if delivered at higher concentrations than that required to kill HeLa cells that express only endogenous Bcl-2. Using western blot analysis, we compared the signal from various concentrations of purified hGraB with hGraB in lysates from HeLa-Bcl-2 cells treated with NK cells for $3 \mathrm{~h}$ in the presence of $\mathrm{zVAD}-\mathrm{fmk}$.
We calculated that NK-treated HeLa-Bcl-2 cells contained between 600 and $1200 \mathrm{nM}$ of hGraB (Figure 3c and Supplementary Figure 2). While this analysis can provide only an approximation of the effective concentration of hGraB, these data suggest that NK cells are capable of delivering at least $125 \mathrm{nM}$ hGraB to HeLa-Bcl-2 cells.

Apoptosis is generally believed to be orchestrated by caspase proteases. We therefore wished to determine whether caspases play a role in hGraB-induced apoptosis of HeLa-Bcl-2 cells. We found that HeLa-Bcl-2 cells treated with hGraB (125 nM) stained positive with zVAD-fmk-FITC, a fluorescent peptide that binds active caspases (Figure $3 a$ ) and zVAD-fmk inhibited PS exposure on hGraB-treated HeLa-Bcl-2 cells (Figure $3 b$ ), an event that is specifically orchestrated by caspases. ${ }^{27}$ zVAD-fmk also blocked hGraBinduced death of Jurkat-Bcl-2, 143B-Bcl-2 and FDCP1-Bcl-2 cells (not shown). zVAD-fmk has been reported to block calpain and other cysteine proteases; ${ }^{28-30}$ however, we found that another caspase inhibitor Q-VD-OPh also blocked hGraB-induced apoptosis of HeLa-Bcl-2 cells (Figure $3 \mathrm{c}$ ), but cathepsin and calpain inhibitors did not (Figure $3 b$ and $c$ and Supplementary Figure 3 ). This confirms the specific involvement of caspases in hGraB-induced apoptosis of HeLa-Bcl-2 cells. Consistent with the previous results, lower concentrations of hGraB $(12.5 \mathrm{nM})$ activated caspases and induced PS exposure in HeLa cells, but not in HeLa-Bcl-2 cells, (Figure 3 ) showing that only high concentrations of hGraB bring about caspase activation when Bcl-2 is overexpressed.

hGraB-induced caspase activation in HeLa-Bcl-2 cells does not involve MOMP or direct processing of caspases to their fully mature form. In cell-free extracts, hGraB has been shown to cleave caspase- 8 and caspase-10 to partially processed forms but caspase-3 was required to cleave these caspases to their mature forms. ${ }^{1}$ hGraB also cleaved caspase-3 and caspase-7 to intermediate-sized fragments that underwent autoprocessing to their mature forms. In cells, the autoprocessing step was blocked by IAPs and release of cyt $c$ and SMAC was required to permit full maturation of these caspases. As overexpression of $\mathrm{Bcl}-2$ blocks release of cyt $c$ and SMAC in HeLa cells, ${ }^{8}$ it was unclear how higher concentrations of hGraB could activate caspases in HeLa-Bcl-2 cells.

One possibility was that higher concentrations of hGraB activated more Bid, or additional pro-apoptotic Bcl-2 family members, to overcome Bcl-2 and trigger caspase-independent MOMP. Consistent with the previous results, cyt $c$ and SMAC were released from mitochondria of HeLa cells treated with hGraB (12.5 nM) in a caspase-independent manner. Cyt $c$ and SMAC were also released from mitochondria of HeLa$\mathrm{Bcl}-2$ cells treated with $125 \mathrm{nM}$ hGraB; however, this was completely blocked by zVAD-fmk (Figure $4 \mathrm{a}$ and b). We also followed the localization of cyt $c$ tagged with green fluorescent protein (cyt $c$-GFP) by time-lapse confocal microscopy (Supplementary movies 8 and 9). Cyt $c$-GFP release was quantitated as a reduction in the variance of fluorescent intensity across individual cells. ${ }^{31}$ We observed rapid cyt $c$-GFP release from mitochondria of individual HeLa cells treated with hGraB $(12.5 \mathrm{nM})$ in the presence or absence of 


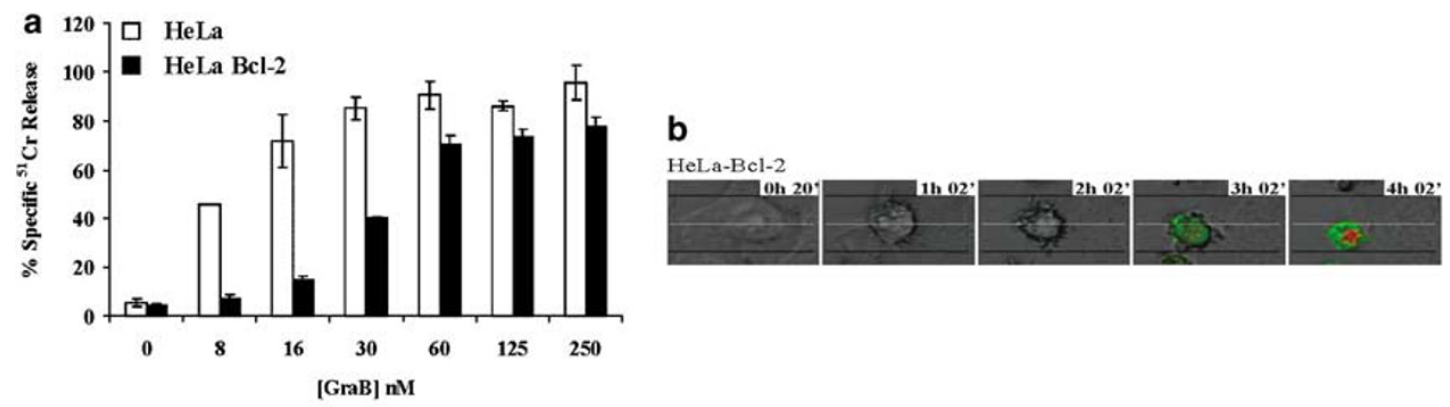

C

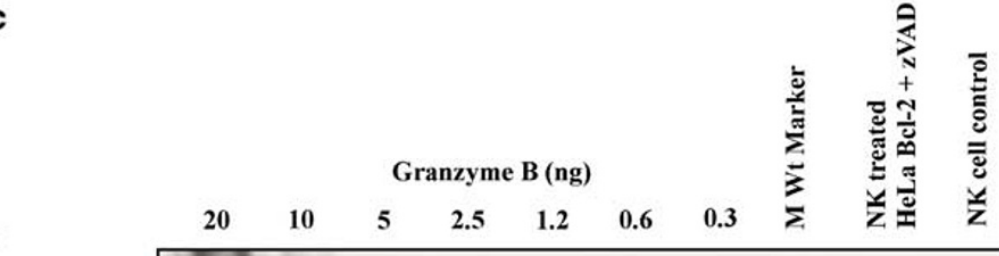

I

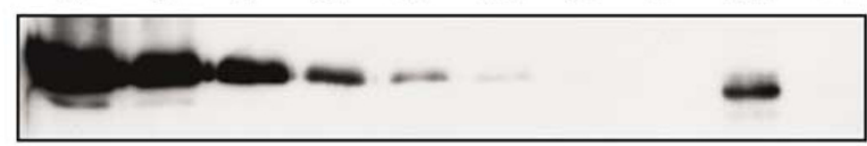

II

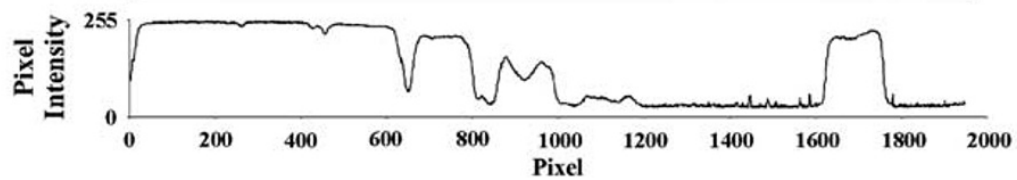

III

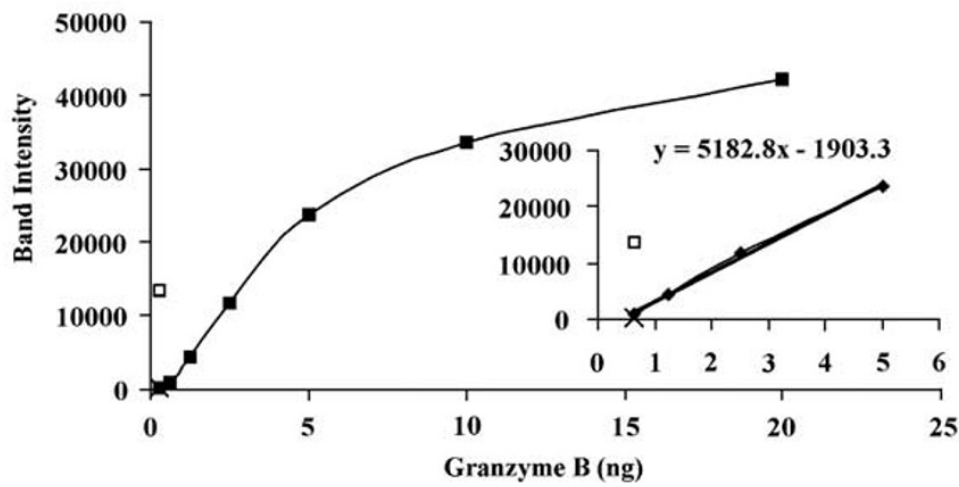

Figure $2 \mathrm{hGraB}$ induces apoptosis in HeLa-Bcl-2. (a) HeLa or HeLa-Bcl-2 cells treated with various concentrations of hGraB in the presence of perforin ( $1 \mathrm{nM}$ ) were assayed for cell death by release of ${ }^{51} \mathrm{Cr}$ that had been preloaded into the target cells. (b) HeLa-Bcl-2 cells treated with $\mathrm{hGraB}(125 \mathrm{nM})$ and perforin ( $\left.1 \mathrm{nM}\right)$ were followed by time-lapse microscopy. Images of morphology (gray), annexin V-FITC (green) and propidium iodide (red) were obtained every 5 min. Representative overlaid images of one cell (adherent (20 $\mathrm{min}$ ) rounding ( $1 \mathrm{~h} 2 \mathrm{~min})$, blebbing ( $2 \mathrm{~h} 2 \mathrm{~min})$, annexin $\mathrm{V}+\mathrm{ve} / \mathrm{Pl}-\mathrm{ve}(3 \mathrm{~h} 2 \mathrm{~min})$ and annexin $\mathrm{V}+\mathrm{ve} / \mathrm{PI}+\mathrm{ve}(4 \mathrm{~h} 2 \mathrm{~min})$ ) are shown. A movie of this cell and graphs of a line scan (indicated by the white line) showing the maximum intensity of morphology, annexin V (green) and propidium iodide (red) is shown in Supplementary movie 7. (c) (i) Purified granzyme B (0.3-20 ng) and lysates from $4 \times 10^{4} \mathrm{NK}$-treated HeLa-Bcl-2 cells and $0.4 \times 10^{4} \mathrm{NK}$ cells (equivalent to the contaminating NK cells in the HeLa-Bcl-2 cells) were subjected to western blotting. (ii) A line (200 pixels wide (the approximate height of gel shown)) was drawn across the blot and (255 minus the minimum intensity (blackest pixel)) was plotted for each point along that line. The intensity of signal for hGraB in the HeLa-Bcl-2 cells was fully within the dynamic range of the film. (iii) The intensity of signal for each concentration of purified GraB was calculated using Image $\mathrm{J}$ software and the slope of the graph $(y=5182.8 \times(-1903.3))$ was calculated for the linear region of the graph (inset). From this, we calculated that there was $2.6 \mathrm{ng} \mathrm{hGraB} \mathrm{in} \mathrm{the} \mathrm{HeLa-Bcl-2} \mathrm{sample} \mathrm{[(13589} \mathrm{+} \mathrm{1903.3)/5182.8]-[(266} \mathrm{+} \mathrm{1903.3)/5182]}$ where 13589 (y1) was the intensity of signal from hGraB in the HeLa-Bcl-2 cells and $266(y 2)$ was the signal intensity for hGraB in the contaminating NK cells. Although we loaded lysates from $4 \times 10^{4} \mathrm{HeLa}-\mathrm{Bcl}-2$, only $2.6 \times 10^{4}(66 \%)$ of these cells would have died in the absence of ZVAD-fmk. The average size of our HeLa-Bcl-2 cells was $2.66 \mathrm{pl}$ (Sysmex automated blood cell counter, Mundelein, IL, USA); therefore, we effectively loaded lysates from $69 \mathrm{nl}$ of $\left(2.66 \mathrm{pl} \times 2.6 \times 10^{4}\right)$ of HeLa-Bcl-2 cells that contained hGraB. hGraB was therefore present in hNK-treated HeLa-Bcl-2 cells at a concentration of $2.6 \mathrm{ng}$ per $69 \mathrm{nl}, 38 \mu \mathrm{g} / \mathrm{ml}$ or $1200 \mathrm{nM}$ (based on the molecular weight of 32 000). We repeated this western blot using $10 \times$ the concentration of NK cell lysate and estimated that the concentration of hGraB was only $625 \mathrm{nM}$ (Supplementary Figure 2). It is noteworthy that the hGraB in the HeLa-Bcl-2 cells was slightly smaller than the purified GraB, probably due to posttranslational modification, but was the same size as hGraB detected in human NK cells (Supplementary Figure 2)

zVAD-fmk (Supplementary movie 8), and this correlated with a decrease in fluorescent variance (Figure 4c). We did not observe any cyt $c$-GFP release in HeLa-Bcl-2 cells treated with hGraB (125 nM) in the presence or absence of zVAD-fmk
(Supplementary movie 9), nor did we observe any significant decrease in fluorescent variances in HeLa-Bcl-2 cells treated with hGraB (125 nM) in the presence of zVAD-fmk (Figure 4c). As we used two independent quantitative assays (FACS and 


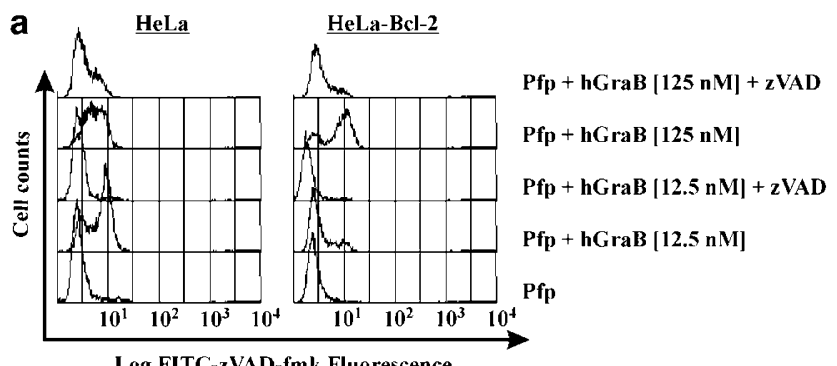

Log FITC-zVAD-fmk Fluorescence
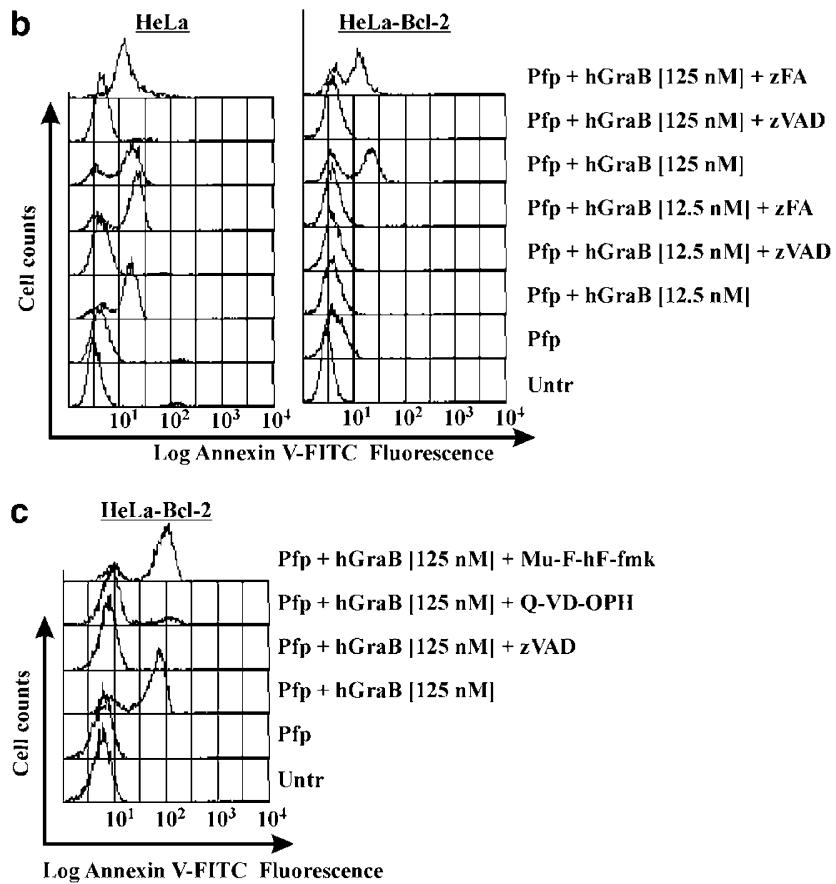

Figure 3 hGraB-induced apoptosis of HeLa-Bcl-2 cells is caspase dependent. HeLa and HeLa-Bcl-2 cells treated with hGraB (12.5 or $125 \mathrm{nM}$ as indicated) and perforin $(1 \mathrm{nM})$ for $4 \mathrm{~h}$ in the presence or absence of ZVAD-fmk $(100 \mu \mathrm{M})$, zFA-fmk $(100 \mu \mathrm{M})$, mF-hF-fmk $(100 \mu \mathrm{M})$ or Q-VD-fmk $(10 \mu \mathrm{M})$ were stained with (a) FITCzVAD-fmk or (b and $\mathbf{c}$ ) annexin V-FITC and assayed by flow cytometry

time-lapse confocal microscopy) and failed to detect any significant release of cyt $c$ from mitochondria of HeLa-Bcl-2 cells treated with hGraB in the presence of zVAD-fmk, we concluded that hGraB-mediated activation of caspases in $\mathrm{HeLa}-\mathrm{Bcl}-2$ must occur upstream and independent of MOMP.

Following initial cleavage by $\mathrm{hGraB}$, caspase-7 and caspase-3 undergo autolytic cleavage after Asp residues to generate the mature protease. As hGraB and these caspases share similar substrate specificity, it was possible that higher concentrations of hGraB bypass the autoprocessing step and directly process these caspases to their mature forms. We therefore used western blot analysis to assay hGraBmediated cleavage of caspases in HeLa and HeLa-Bcl-2 cells in the presence and absence of zVAD-fmk. These experiments were performed in the presence of MG132 to prevent proteasomal degradation of the partially processed fragments (Supplementary Figure 4). We found that pro-caspase-3 and pro-caspase-7 were fully processed (to p17 and p12 fragments, respectively) in HeLa-Bcl-2 cells treated with $125 \mathrm{nM}$ hGraB; however, both caspases were only partially
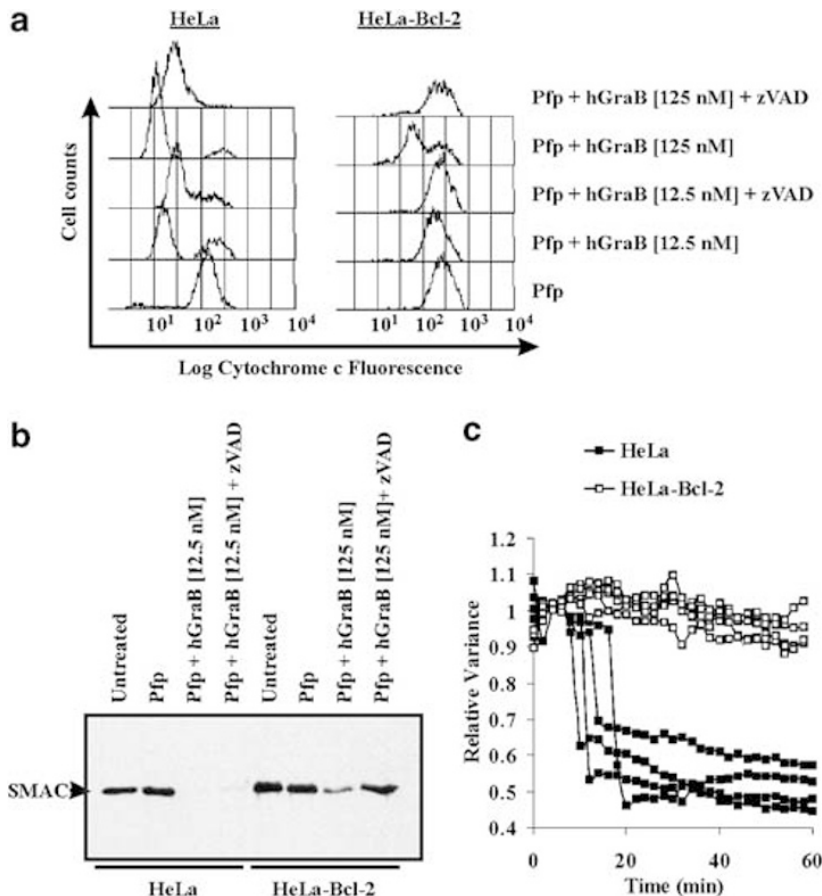

Figure $4 \mathrm{hGraB}$ induces caspase activation in HeLa-Bcl-2 cells, independent of mitochondrial outer membrane permeabilization. HeLa and HeLa-Bcl-2 cells treated with $\mathrm{hGraB}$ ( 12.5 or $125 \mathrm{nM}$ as indicated) and perforin $(1 \mathrm{nM})$ for $2 \mathrm{~h}$ in the presence or absence of ZVAD-fmk $(100 \mu \mathrm{M})$ were permeabilized with digitonin to release soluble proteins in the cytoplasm. The cell pellet was either (a) fixed and stained with primary anti-cytochrome $c$ and secondary anti-mouse-PE and analyzed by flow cytometry or (b) lysed and subjected to western blot analysis with anti-SMAC. (c) Release of cyt $c$-GFP from mitochondria was quantitated by measuring the variance in green fluorescence intensity across individual cells ${ }^{31}$ and plotted against time

processed in the presence of zVAD-fmk (Figure 5). Importantly, hGraB-mediated cleavage of pro-caspase-7 and pro-caspase-3 was not due to adventitious cleavage by hGraB following target cell lysis, as we obtained similar results when the HeLa-Bcl-2 cells were lysed in buffer containing dichloroisocoumarin, which directly blocks hGraB activity (not shown). We also found that hGraB cleaved pro-caspase-8 to a p43 fragment in the presence or absence of ZVAD-fmk, but did not cleave caspase- 8 to the mature 18 form detected during TRAIL-induced apoptosis (Figure 5). Caspase-9 was cleaved to its fully active form only during hGraB-induced apoptosis of HeLa cells but not during hGraB-induced apoptosis of HeLa-Bcl-2 cells. Collectively, these data show that high concentrations of hGraB do not directly cleave caspase- $3,-7,-8$ or -9 to their fully active form in intact HeLa-Bcl-2 cells.

Caspases play a critical role in hGraB-induced apoptosis and hNK-induced death of Bcl-2-overexpressing cells. Previous studies have shown that caspases do not play a critical role in hGraB-induced apoptosis, as cells treated with $h \mathrm{GraB}$ in the presence of ZVAD-fmk did not survive in long-term assays of clonogenicity or proliferation. ${ }^{8}$ Recent studies showed that caspases are critical for mGraB-induced apoptosis, as cells treated with $\mathrm{mGraB}$ in the presence of caspase inhibitors did continue to proliferate.$^{20} \mathrm{It}$ was proposed that MOMP did not play a role in the mouse 


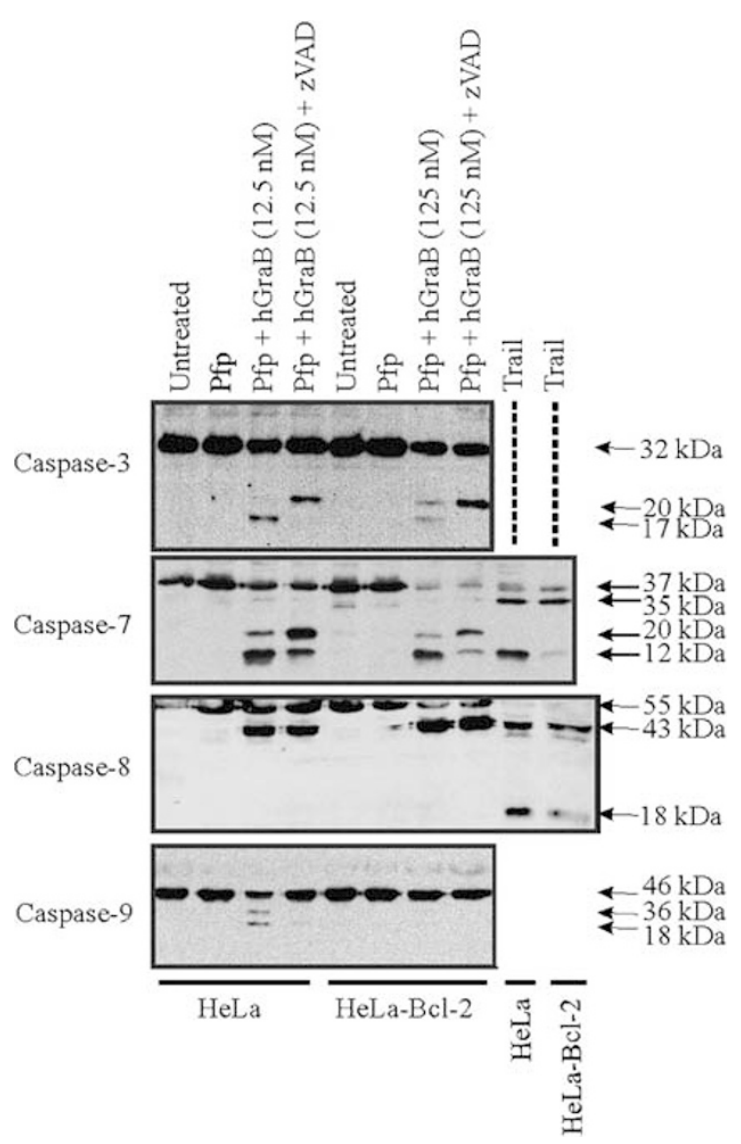

Figure $5 \mathrm{hGraB}$ does not directly cleave caspase- $-3,-7,-8$ or -9 to their mature forms. Lysates from HeLa and HeLa-Bcl-2 cells treated with hGraB (12.5 or $125 \mathrm{nM}$ as indicated) and perforin $(1 \mathrm{nM})$ or human leucine zipper TRAIL $(230 \mathrm{ng} / \mathrm{ml})$ for $2 \mathrm{~h}$ in the presence or absence of ZVAD-fmk $(100 \mu \mathrm{M})$ and MG132 $(1 \mu \mathrm{M})$ were subjected to western blot analysis for caspase-3, $-7,-8$ and -9

as $m G$ raB did not efficiently cleave Bid. We therefore wished to determine whether caspases play a critical role in $\mathrm{hGraB}$-induced apoptosis when MOMP is blocked by overexpression of Bcl-2. Consistent with previous studies, zVADfmk blocked hGraB-induced apoptosis of HeLa cells but these cells failed to survive in clonogenic assays (Figure 6a and b). In contrast, zVAD-fmk blocked hGraB-induced apoptosis of HeLa-Bcl-2 cells and these cells did survive and proliferate in long-term clonogenic assays (Figure 6a and $b$ ). From these studies, it was clear that the combined effect of overexpression of $\mathrm{Bcl}-2$ and inhibition of caspases was sufficient to confer survival following treatment with high concentrations of hGraB but overexpression of $\mathrm{Bcl}-2$ or inhibition of caspases alone was not. We did observe a small but significant loss of clonogenic survival when HeLa-Bcl-2 cells were treated with low concentrations of GraB $(12.5 \mathrm{nM})$ in the presence of zVAD-fmk; however, overexpression of XIAP, a natural inhibitor of caspase autolysis, rescued $100 \%$ of these cells suggesting that ZVAD-fmk itself may have limited toxicity in these assays. Overexpression of XIAP also blocked apoptosis of HeLa-Bcl-2 cells treated with $125 \mathrm{nM}$ $\mathrm{hGraB}$ and a significant number of these cells survived in clonogenic assays but XIAP was less effective in these assays and could be supplemented by adding ZVAD-fmk
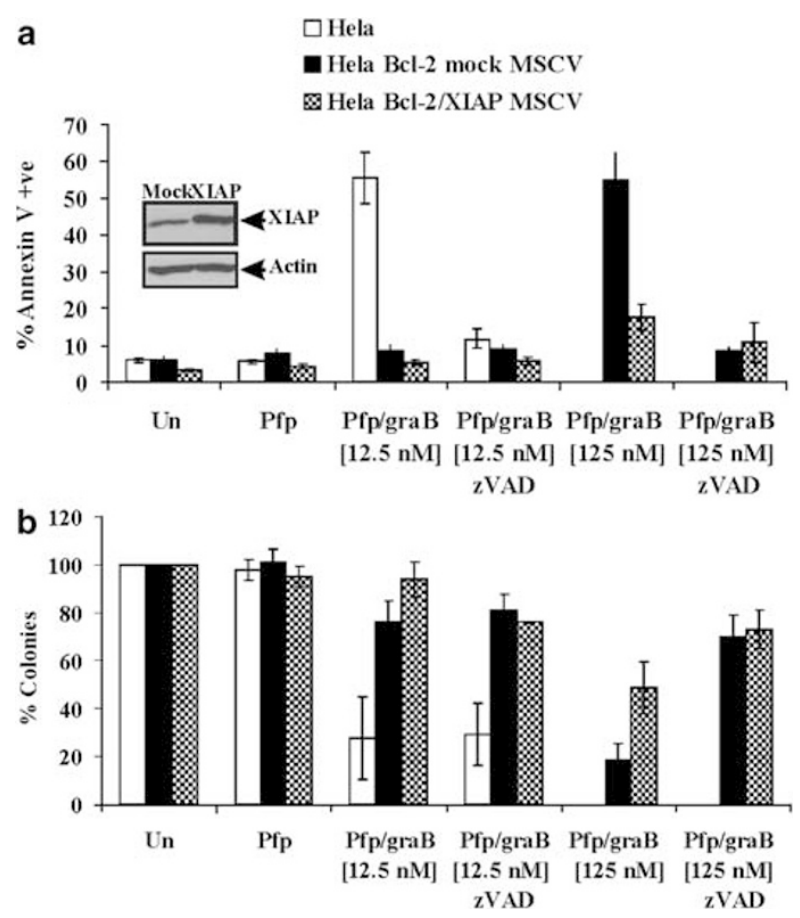

Figure 6 The combined effects of Bcl-2 and inhibition of caspase activity block hGraB-induced apoptosis of HeLa-Bcl-2 cells. HeLa-Bcl-2 cells were transduced with MSCV-IRES-GFP and MSCV-XIAP-IRES-GFP and sorted by FACS. (inset) Cells were tested for XIAP expression by western blotting. (a) HeLa, HeLa-Bcl-2Mock or HeLa-Bcl-2-XIAP cells treated with hGraB (12.5 or $125 \mathrm{nM}$ as indicated) and $1 \mathrm{nM}$ perforin in the presence or absence of ZVAD-fmk $(100 \mu \mathrm{M})$ for $4 \mathrm{~h}$ were stained with annexin V-FITC and assayed by flow cytometry. Data reported are the average of five independent experiments \pm S.E.M. (b) HeLa, HeLa-Bcl-2-Mock or HeLa-Bcl-2-XIAP cells treated with $\mathrm{hGraB}$ and $1 \mathrm{nM}$ perforin in the presence or absence of ZVAD-fmk $(100 \mu \mathrm{M})$ were plated after $1 \mathrm{~h}$ and colonies were counted after 7 days. Data reported are the average of four independent experiments \pm S.E.M.

(Figure 6). This may be because the level of XIAP was not sufficient to fully inhibit caspases activated by $125 \mathrm{nM}$ hGraB in all cells. These data show that direct initiation of caspase processing plays a critical role during hGraB-induced apoptosis but only when the mitochondrial pathway is blocked.

To investigate whether blocking caspase activity and preventing MOMP could also block the cytotoxic effect of hGraB delivered by intact $\mathrm{CL}$, we treated $\mathrm{HeLa}$ and HeLa-Bcl-2 cells with NK cells in the presence or absence of ZVAD-fmk. NK cells induced apoptosis in a significant number of HeLa and HeLa-Bcl-2 cells within $2 \mathrm{~h}$ in the absence of $\mathrm{ZVAD}-\mathrm{fmk}$, but the majority of cells maintained a flattened morphology in the presence of zVAD-fmk (Figure 7a). Indeed, time-lapse movies revealed that while $\sim 75 \%$ of HeLa-Bcl-2 were killed by NK cells in the absence of zVAD-fmk, less than $10 \%$ of HeLa-Bcl-2 were killed in the presence of zVAD-fmk (Supplementary movies 10 and 11). Although HeLa cells treated with NK cells in the presence of ZVAD-fmk did not round up, cyt $c$ was released from the mitochondria into the cytoplasm (Figure $7 \mathrm{~b}$ ) and they did not survive in clonogenic assays (Figure 7c). Cyt $c$ was not released from mitochondria of HeLa-Bcl-2 cells incubated with NK cells in the presence of zVAD-fmk (Figure 7b), and these cells did survive and 
a

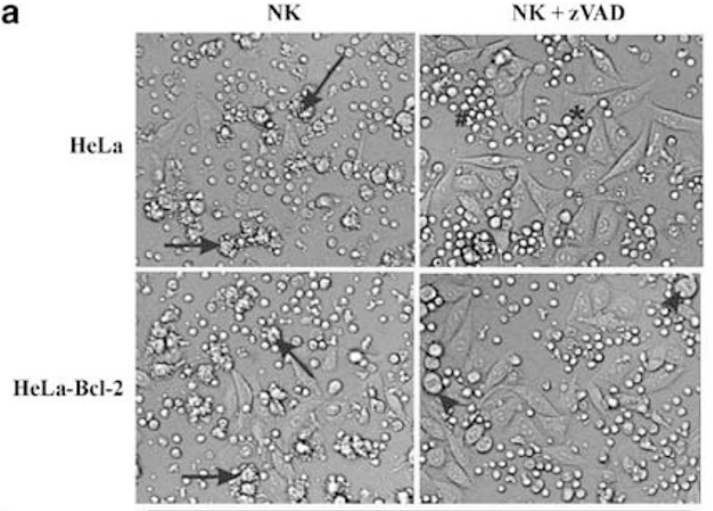

b
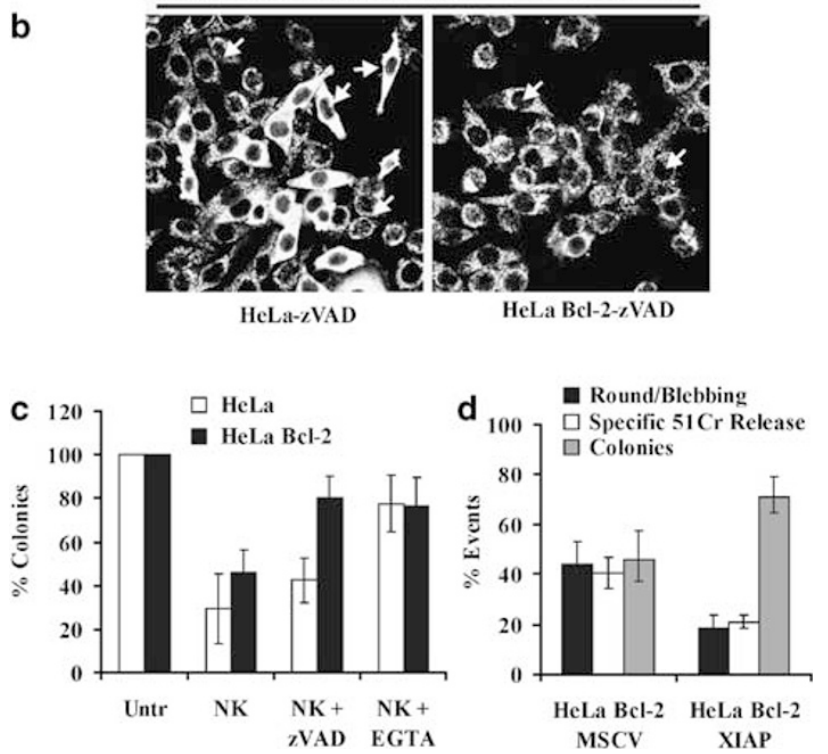

Figure 7 The combined effects of $\mathrm{Bcl}-2$ and caspase inhibitors block the cytotoxic effects of hGraB during NK-induced cell death. (a) HeLa and HeLa-Bcl-2 cells were treated with NK cells in the presence or absence of ZVAD-fmk (100 $\mu \mathrm{M})$ and followed by time-lapse microscopy. DIC images taken immediately after NK cells were added and after $2 \mathrm{~h}$ are presented. The HeLa cells (indicated by *) are large and flat. The NK cells (indicated by \#) are small and round. Arrow heads indicate mitotic cells. Arrows indicate apoptotic cells. (b) HeLa and HeLa-Bcl-2 cells treated with NK cells in the presence of ZVAD-fmk $(100 \mu \mathrm{M})$ for $2 \mathrm{~h}$ were fixed and stained for cyt $c$. Arrow heads indicate cells in which cyt $c$ is in the mitochondria, arrows indicate cells in which cyt $c$ is in the cytoplasm. (c) HeLa and HeLa-Bcl-2 cells treated with NK cells at an effector-to-target ratio of $2: 1$ for $1 \mathrm{~h}$ in the presence or absence of zVAD-fmk $(100 \mu \mathrm{M})$ were plated and colonies were counted after 7 days. Data reported are the average of five independent experiments \pm S.E.M. (d) HeLa-Bcl-2-Mock and HeLa-Bcl-2-XIAP cells preloaded with ${ }^{51} \mathrm{Cr}$ were treated with NK cells and specific ${ }^{51} \mathrm{Cr}$ release was assayed at $4 \mathrm{~h}$ (error bars are S.E.M. of $n=6)$. Similar cells were treated with NK cells for $1 \mathrm{~h}$ and plated for colony-forming assays or followed by time-lapse microscopy. The percentage apoptosis in the timelapse movies was scored after $4 \mathrm{~h}$ and colonies were counted after 7 days (error bars are S.E.M. of $n=4$ )

continued to proliferate (Figure 7c). Similarly, we found that HeLa-Bcl-2 cells overexpressing XIAP were more resistant to NK-induced death than HeLa-Bcl-2-MSCV cells and more HeLa-Bcl-2-XIAP cells survived in colony-forming assays (Figure 7d). As overexpression of $\mathrm{Bcl}-2$ in combination with inhibition of caspase activity, but not either alone, blocked NK-induced death, these data demonstrate the critical role played by both caspases and MOMP in this process.

\section{Discussion}

Purified GraB can cleave almost 30 substrates when added to cell lysates and may therefore trigger various pathways to cell death. The relative contribution of these pathways to CL-induced death is not clear. Studies using CL from mice deficient in GraB have been influential in elucidating the contribution of GraB to CL-induced death; however, recent studies have shown that $\mathrm{mGraB}$ has different substrate preference to hGraB. ${ }^{19-21}$ It is therefore essential to understand the mechanism by which human CL utilize hGraB to kill their targets. In this study, we have closely followed the death of cells treated with hGraB or hNK cells, in which hGraB was crucial for inducing death. Both hNK cells and hGraB induced apoptosis of HeLa cells by activating mitochondria-dependent and mitochondria-independent pathways to caspase activation. Inhibition of both of these pathways together, but not either alone, blocked the cytotoxic effects of purified hGraB or hNK cells. These studies demonstrate the importance of the Bcl-2-regulated mitochondrial pathway in hGraB-induced apoptosis while elucidating a bona fide role for alternative pathways to caspase activation.

Hierarchical pathways to hGraB-mediated caspase activation. Previous studies reported that MOMP was not required for GraB-mediated activation of caspases and that MOMP was simply part of a caspase amplification loop, ${ }^{3,17,18}$ but other studies predicted that MOMP was critical for GraBinduced activation of caspases. ${ }^{4-6,8,24}$ Our current data show that hGraB can induce MOMP-independent activation of caspases in cells but activation of this pathway required significantly higher concentrations (5- to 10-fold) of hGraB than that required to activate the MOMP-dependent pathway. This suggests that in a cell biological system, these two pathways coexist, but they are activated in a hierarchical fashion depending on the concentration of $\mathrm{GraB}$ delivered to the target rather than in a time-dependent manner that would be predicted if MOMP was part of an amplification loop. Although we still do not know the exact concentration of hGraB delivered by NK cells into the target cell cytoplasm, our data suggest that NK cells must be capable of delivering sufficient hGraB to activate both pathways. The relative importance of these pathways to NK-induced death may become apparent only when the alternate pathway is blocked or if viral inhibitors partially block hGraB thereby reducing the effective concentration of hGraB delivered.

Although our studies indicate that hGraB can trigger mitochondria-independent activation of caspases, they did not resolve how this occurred. One possibility may be that XIAP levels in HeLa cells are sufficient to inhibit a limited pool of caspases cleaved by low concentrations of hGraB but cannot inhibit autolytic activation of a larger pool of caspases cleaved by higher concentrations of hGraB. This model could explain why MOMP is required for (Bcl-2 can block) full activation of caspases in cells treated with $12.5 \mathrm{nM} \mathrm{hGraB}$ but is not required for (Bcl-2 cannot block) activation of caspases in cells treated with $125 \mathrm{nM}$ hGraB (Figure 8). Importantly, overexpression of XIAP alone would not be expected to block hGraB- or NK-induced apoptosis in this model as release of SMAC from the mitochondria would deregulate XIAP directly. 
a Endogenous Bcl-2 and XIAP

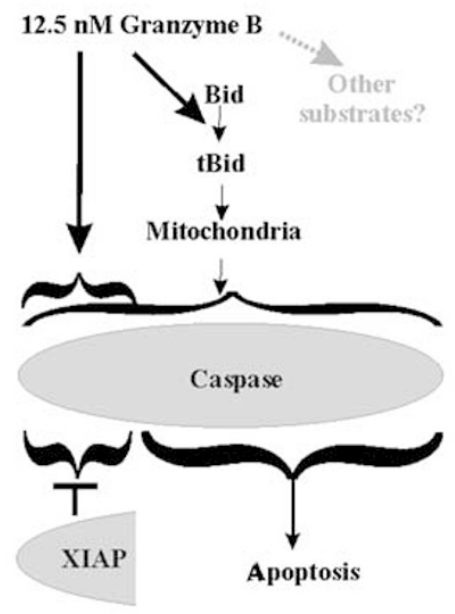

c

$$
\frac{\text { Overexpressed Bcl-2 and }}{\text { endogenous XIAP }}
$$

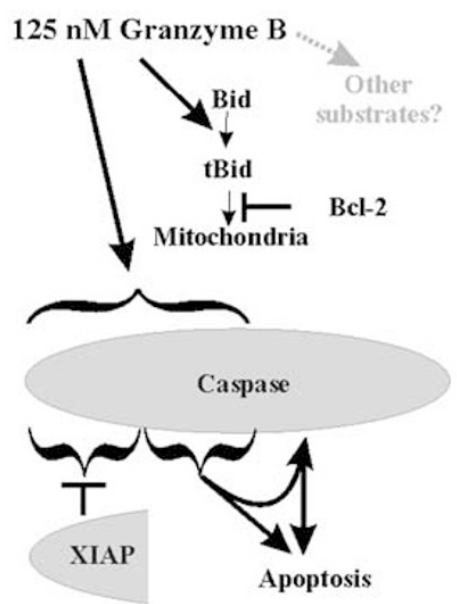

b Overexpressed Bcl-2 and endogenous XIAP

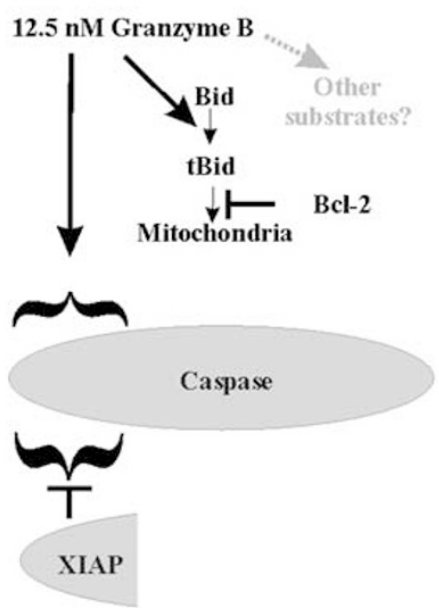

d Overexpressed Bcl-2 and XIAP endogenous XIAP

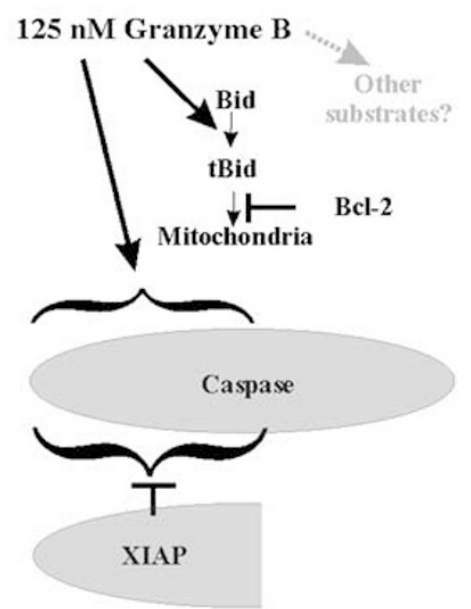

Figure 8 Hierarchical pathways to hGraB-induced apoptosis. (a) At low nanomolar concentrations, hGraB targets both caspases and Bid. The level of caspase cleavage is kept in check by a pool of XIAP. Bid triggers mitochondrial outer membrane permeabilization ensuring full activation of caspases via cyt $c$-mediated activation of the apoptosome and SMAC/Diablo-mediated deregulation of XIAP. (b) In cells overexpressing Bcl-2, hGraB (low nM) cleaves caspases and Bid; however, mitochondria remain intact and the small pool of caspases cleaved to intermediate fragments are blocked from autoactivation by XIAP. (c) In cells overexpressing Bcl-2, higher concentrations of $h \mathrm{GraB}$ cleaves Bid, but the mitochondria remain intact. This concentration of $\mathrm{hGraB}$ partially processes a larger pool of caspases than are blocked by the endogenous pool of XIAP. The unbound caspases autoactivate and initiate a caspase cascade ensuring death of the cell by apoptosis. (d) In cells overexpressing Bcl-2 and XIAP, the higher concentration of hGraB cleaves Bid and partially processes a large pool of caspases; however, Bcl-2 protects the integrity of mitochondria and the increased pool of XIAP binds to and blocks the autolytic cleavage of the caspases. This cartoon seeks to address the involvement of Bid/Bcl-2 and direct activation of caspases but does not preclude the possibility that hGraB also cleaves other substrates (gray arrow)

The importance of XIAP as a caspase inhibitor may therefore be apparent only when MOMP is blocked or cannot be activated efficiently.

Alternate pathways to CL-induced death. Previous studies found that although $\mathrm{Bcl}-2$ and caspase inhibitors blocked GraB-induced apoptosis, they could not prevent $\mathrm{CL}$-induced death. We have identified a model in which inhibition of GraB blocked NK-induced death. In this model, overexpression of $\mathrm{Bcl}-2$ and inhibition of caspase activity did block NK-induced death. Critically, our study demonstrates that blocking both pathways but not either alone was required to block this process. It is unlikely that $\mathrm{Bcl}-2$ and caspase inhibitors together will block CL-induced death in all models. For example, we found that NK cells stimulated with high concentrations of rIL-2 or $25 \mathrm{U}$ rIL2 for longer than 2 days killed their targets by a lytic death that we would not expect to be blocked by inhibiting apoptosis. Interestingly, we observed that cyt $c$-GFP was released from mitochondria of cells that were killed by NK-induced lysis and the nuclei became condensed suggesting that although GraB initiated apoptosis in these cells, they were already committed to death by lysis (Supplementary movie 12). If previous models used CL that killed their targets by lysis, 
overexpression of Bcl-2 or inhibition of caspase activity might have prevented GraB-mediated events, but would have failed to block death. These studies highlight the importance of determining the specific nature of $C L$-induced death in specific models for $\mathrm{CL}$-induced death. Allogenic CTL and LAK cells from $\mathrm{GraA}^{-1-} \mathrm{GraB}^{-1-}$ mice are still cytotoxic and inhibition of GraB does not always block CL-induced death. ${ }^{24,25,32-35}$ It is therefore possible that $C L$ from rodents or CL activated by different mechanisms may kill their targets by nonapoptotic/nonlytic processes. In support of this, humans express different granzymes to rodents and NK cells express different granzymes to CTL. Individual CL also expresses different granzymes ${ }^{36,37}$ and it is therefore possible that blocking apoptosis only prevents death induced by a subset of hNK but other hNK cells can kill by nonapoptotic processes. Any such subset of NK cells did not appear to represent a sufficiently large population in our model to affect the clonogenic potential of the HeLa-Bcl-2 cells.

Why does hGraB activate two pathways to death? It is intriguing to speculate why hGraB would activate two pathways to apoptosis in a target cell. The host immune system has evolved in conflict with viruses and several viruses express homologs of $\mathrm{Bcl}-2$ (e.g., Epstein-Barr virus BHRF1) or inhibitors of caspase (e.g., baculovirus IAPs). The immune system must have evolved pathways to circumvent viral proteins that block specific pathways to apoptosis. Interestingly, while inhibition of MOMP or caspases alone did not prevent NK-induced death, inhibition of both pathways did permit clonogenic survival of target cells. It is unclear what consequences this may have for the body; however, it may be imagined that if a virus that encodes a homolog of Bcl-2 infected a cell in which caspase activity was impaired (or vice versa), that cell may have the potential to survive NK-induced death. Such an event may contribute to virus persistence unless the infected cell is cleared by another mechanism. Similarly, resistance to death is one of the properties of tumor cells that contribute to the malignant phenotype. Blocking MOMP and caspase activity may therefore prevent NK-induced death and contribute to tumorigenesis. Indeed, while altered levels of Bcl-2 family members and IAPs are found in some cancers, they are not potent oncogenes unless they exert their effects in conjunction with other oncogenes.

\section{Materials and Methods}

Materials. Granule proteins were isolated using established methods. ${ }^{38,39}$ Annexin V-FITC, anti-cytochrome $c$ (clone 6HB12), anti-XIAP and anti-caspase-3 were from BD Pharmingen (San Diego, CA, USA). Anti-caspase-8 and anticaspase-9 were from Millipore. Z-Val-Ala-Asp-CH2F (zVAD)-fmk and Q-VD-OPH were from Enzyme Systems Products (Dublin, CA, USA) and mF-hF-fmk was from BioMol (Plymouth Meeting, PA, USA). ${ }^{51} \mathrm{Cr}$ (as sodium dichromate) was from Amersham Biosciences (UK). Anti-SMAC was from ProSci (San Diego, CA, USA).

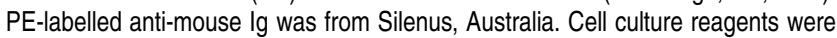
from Gibco-BRL (Melbourne, Australia). All other chemicals were from Sigma (St. Louis, IL, USA).
}

Cell culture. HeLa cells were cultured at $37^{\circ} \mathrm{C}$ in a humidified $\mathrm{CO}_{2}$ incubator in DMEM supplemented with $2 \mathrm{mM}$ glutamine and $10 \%$ fetal bovine serum (FBS). HeLa-BCl-2 were transduced with MSCV-IRES-GFP encoding XIAP. Cells were sorted for GFP expression by FACS and expression of XIAP was assayed by western blotting. Human NK cells were cultured in RPMI-1640 containing $2 \mathrm{mM}$ glutamine, $10 \% \mathrm{FBS}, 100 \mu \mathrm{M}$ nonessential amino acids, $1 \mathrm{mM}$ sodium pyruvate, $50 \mu \mathrm{M} \beta$-mercaptoethanol, $100 \mu \mathrm{g} / \mathrm{ml}$ streptomycin and $100 \mathrm{U}$ penicillin and $25 \mathrm{U} / \mathrm{ml}$ rlL-2.

Isolation of NK cells. Human NK cells were isolated by negative selection using an MACS-based isolation kit (Milteni Biotech, Germany). Briefly, cells were incubated with a cocktail of biotin-conjugated monoclonal antibodies (against CD3, CD4, CD14, CD15, CD19, CD36, CD123 and CD235a) for 15 min at $4^{\circ} \mathrm{C}(10 \mu \mathrm{l}$ of cocktail per $1 \times 10^{7}$ cells). Twenty microliters of anti-biotin microbeads were added per $1 \times 10^{7}$ cells and incubated for a further $15 \mathrm{~min}$ at $4^{\circ} \mathrm{C}$. Cells were washed and resuspended in PBS supplemented with $0.5 \% \mathrm{FBS}$, and NK cells were isolated by negative selection using a deplete program on an autoMACS ${ }^{\mathrm{TM}}$ Seperator.

Assaying cell death. Cell death was measured by standard ${ }^{51} \mathrm{Cr}$ release, annexin V binding, cytochrome $c$ release or clonogenic assays ${ }^{8,39,40}$ (Supplementary Information). For NK assays, effector cells and target cells were washed with DMEM. For hGraB assays, target cells were washed in Hank's balanced salt solution (HBSS) containing $\mathrm{CaCl}(1 \mathrm{mM})$, Hepes- $\mathrm{NaOH}(20 \mathrm{mM})$ and BSA $(0.3 \%)$ and resuspended at $2.5 \times 10^{5}$ cells $/ \mathrm{ml}$. Perforin $(1 \mathrm{nM})$ and GraB (at the concentrations indicated) were added to the cells in the presence or absence of zVAD-fmk $(100 \mu \mathrm{M})$, zFA-fmk $(100 \mu \mathrm{M})$, mF-hF-fmk $(100 \mu \mathrm{M})$ or Q-VD-OPH $(20 \mu \mathrm{M})$. For clonogenic assays, target cells were treated with GraB/perforin or lethally irradiated NK cells ( $40 \mathrm{~Gy}$ ) for $1 \mathrm{~h}$ and plated in flat-bottom 24-well plates in serial dilution. Cells were fixed with $100 \%$ methanol after 7 days and stained with methylene blue $(0.03 \%)$. Colonies were counted manually.

Time-lapse microscopy. Target cells were plated in flat-bottomed 96-well culture plates overnight at $37^{\circ} \mathrm{C}$ in a humidified $\mathrm{CO}_{2}$ incubator and transferred to a temperature-controlled stage (Prior Proscan; GT Vision) maintained at $37^{\circ} \mathrm{C}$ on an IX-81 microscope (Olympus). NK cells, TRAIL ( $240 \mathrm{ng} / \mathrm{ml})$, annexin V-FITC $(2 \mu \mathrm{g} / \mathrm{ml})$, PI $(0.5 \mu \mathrm{M})$ and zVAD-fmk $(100 \mu \mathrm{M})$ were added to the culture media where indicated and cells were viewed using a $\times 20 \mathrm{LCplanFL} \mathrm{NA} 0.40$ lens (Olympus). Images of DIC, annexin V-FITC (green) and PI (red) were captured at the time intervals indicated using a CCD camera (model ORCA-ER; Hamamatsu) controlled by MetaMorph software (Universal Imaging Corp.). Overlaid images were compiled using MetaMorph software (Universal Imaging Corp.). For GraB assays, cells were washed in $\mathrm{HBSS}$ supplemented with $\mathrm{CaCl}(1 \mathrm{mM})$, Hepes- $\mathrm{NaOH}(20 \mathrm{mM})$ and BSA $(0.3 \%)$. Cells were incubated in $50 \mu \mathrm{l} \mathrm{HBSS}$ and transferred to the microscope stage. Perforin was added to the cells in $50 \mu \mathrm{l}$ of calcium-free HBSS to ensure rapid mixing. Full media ( $100 \mu l$ ) was added 15 min after perforin to maintain the integrity of apoptotic cells.

Immunocytochemistry. Cells were treated in eight-well chamber slides and washed with PBS. Cells were fixed in $3.7 \%$ paraformaldehyde in PBS for 20 min at room temperature followed by permeabilization buffer $(0.05 \%$ saponin, $3 \%$ BSA in PBS) for $1 \mathrm{~h}$ at room temperature. Cells were incubated overnight at $4{ }^{\circ} \mathrm{C}$ with anticytochrome $c$ diluted $1: 200$ in permeabilization buffer, washed in PBS and incubated at room temperature for at least $1 \mathrm{~h}$ in Alexa-594-conjugated secondary antibody in PBS. The cells were washed in PBS and Alexa 594 fluorescence was detected using a Bio-Rad MRC1024ES confocal using a PLAN Apo40X lens (NA $1.25-0.75)$ on a Leica DMRBE microscope.

Western blot. To assay for SMAC release or caspases, treated cells were incubated at $4^{\circ} \mathrm{C}$ for $5 \mathrm{~min}$ with ice-cold cell lysis and mitochondria intact (CLAMI) buffer ( $120 \mathrm{mM} \mathrm{KCl}, 1 \mathrm{mM}$ EDTA, $50 \mathrm{mg} / \mathrm{ml}$ digitonin in PBS). Samples were stained with trypan blue counted to ensure that the plasma membrane disruption of at least $95 \%$ of the cells. Permeabilized cells were pelleted by centrifugation $(400 \times g$ for $5 \mathrm{~min})$. To assay for XIAP or hGraB, whole cells were pelleted by centrifugation $(400 \times g$ for $5 \mathrm{~min})$. Cell pellets were lysed in universal immunoprecipitation buffer (UIB (50 mM Tris- $\mathrm{HCl}$, pH 7.4, $150 \mathrm{mM} \mathrm{NaCl}, 2 \mathrm{mM}$ EDTA, $2 \mathrm{mM}$ EGTA and complete protease inhibitors)) and resolved by SDS-PAGE and transferred to PVDF (Immobilon P) for western blotting. Blots were blocked using $5 \%$ skim milk powder in PBS containing tween (0.05\%). Caspases, XIAP and SMAC were detected using the specific primary antibodies diluted 1:1000 in blocking buffer followed by species-specific secondary antibodies conjugated to horseradish peroxidase. Horseradish peroxidase was detected by enhanced chemi-luminescence-PLUS (Pierce). Each membrane was analyzed for several proteins by reprobing. 
Quantitation of Granzyme B. $2 \times 10^{6} \mathrm{HeLa}-\mathrm{Bcl}-2$ cells were treated with $4 \times 10^{6}$ day 2 stimulated NK cells for $3 \mathrm{~h}$ in the presence or absence of ZVAD-fmk. Sixty six percent of the HeLa-Bcl-2 cells treated in the absence of ZVAD-fmk showed signs of apoptosis within $3 \mathrm{~h}$. NK cells were harvested by washing three times with PBS and then the HeLa-Bcl-2 cells were harvested using PBS/EDTA. Remaining NK cells and NK/HeLa-Bcl-2 conjugates were removed from the HeLa-Bcl-2 sample by MACS separation using beads coated with anti-CD56 and the harvested cells were enumerated. Purified hGraB and cell lysates were subjected to western blot analysis. Image $\mathrm{J}$ was used to generate a standard curve for known concentrations of purified GraB (using Image $\mathrm{J}$ software) and the equation for the slope of the graph in the linear region was used to calculate the amount of $h \mathrm{GraB}$ in the cell lysates.

Acknowledgements. We would like to thank llia Voskobonik (Peter MacCallum Cancer Centre) for helpful discussions, Herb Bull and Nancy Thornberry (MERCK research laboratories) for compound 20, Abbot Laboratories for ABT-737 and Sarah Ellis (Peter MacCallum Cancer Centre) for extensive support of the microscopy experiments. This work was supported by project grants to NJW (454506) and JO (454567) and program grants to JAT, RWJ and PIB from the NH\&MRC Australia. NJW, JO and JS are RD Wright Fellows and JAT is a Senior Principal Research Fellow of the NH\&MRC Australia. RWJ is a Pfizer Senior Research Fellow, Australia. We apologize to those whose papers were not cited due to editorial restrictions.

1. Adrain C, Murphy BM, Martin SJ. Molecular ordering of the caspase activation cascade initiated by the cytotoxic T lymphocyte/natural killer (CTL/NK) protease granzyme B. J Bio Chem 2005; 280: 4663-4673.

2. Darmon AJ, Nicholson DW, Bleackley RC. Activation of the apoptotic protease CPP32 by cytotoxic T-cell-derived granzyme B. Nature 1995; 377: 446-448.

3. Martin SJ, Amarante-Mendes GP, Shi L, Chuang TH, Casiano CA, O'Brien GA et al. The cytotoxic cell protease granzyme $B$ initiates apoptosis in a cell-free system by proteolytic processing and activation of the ICE/CED-3 family protease, CPP32, via a novel two-step mechanism. EMBO J 1996; 15: 2407-2416.

4. Han J, Goldstein LA, Gastman BR, Rabinovitz A, Rabinowich H. Disruption of Mcl-1. Bim complex in granzyme B-mediated mitochondrial apoptosis. J Biol Chem 2005; 280: 16383-16392.

5. Heibein JA, Goping IS, Barry M, Pinkoski MJ, Shore GC, Green DR et al. Granzyme Bmediated cytochrome $c$ release is regulated by the $\mathrm{Bcl}-2$ family members bid and $\mathrm{Bax}$ J Exp Med 2000; 192: 1391-1402.

6. Pinkoski MJ, Waterhouse NJ, Heibein JA, Wolf BB, Kuwana T, Goldstein JC et al. Granzyme B-mediated apoptosis proceeds predominantly through a Bcl-2-inhibitable mitochondrial pathway. J Biol Chem 2001; 276: 12060-12067.

7. Sutton VR, Wowk ME, Cancilla M, Trapani JA. Caspase activation by granzyme $B$ is indirect, and caspase autoprocessing requires the release of proapoptotic mitochondrial factors. Immunity 2003; 18: 319-329.

8. Waterhouse NJ, Sedelies KA, Sutton VR, Pinkoski MJ, Thia KY, Johnstone R et al. Functional dissociation of DeltaPsim and cytochrome $c$ release defines the contribution of mitochondria upstream of caspase activation during granzyme B-induced apoptosis. Cell Death Differ 2006; 13: 607-618.

9. Adrain C, Duriez PJ, Brumatti G, Delivani P, Martin SJ. The cytotoxic lymphocyte protease, granzyme $\mathrm{B}$, targets the cytoskeleton and perturbs microtubule polymerization dynamics. J Biol Chem 2006; 281: 8118-8125.

10. Andrade F, Roy S, Nicholson D, Thornberry N, Rosen A, Casciola-Rosen L. Granzyme B directly and efficiently cleaves several downstream caspase substrates: implications for CTL-induced apoptosis. Immunity 1998; 8: 451-460.

11. Bredemeyer AJ, Townsend RR, Ley TJ. Use of protease proteomics to discover granzyme B substrates. Immunol Res 2005; 32: 143-153.

12. Goping IS, Barry M, Liston P, Sawchuk T, Constantinescu G, Michalak KM et al. Granzyme $\mathrm{B}$-induced apoptosis requires both direct caspase activation and relief of caspase inhibition. Immunity 2003; 18: 355-365

13. Salvesen GS, Dixit VM. Caspase activation: the induced-proximity model. Proc Natl Acad Sci USA 1999; 96: 10964-10967.

14. Alimonti JB, Shi L, Baijal PK, Greenberg AH. Granzyme B induces BID-mediated cytochrome $c$ release and mitochondrial permeability transition. J Biol Chem 2001; 276: 6974-6982

15. Barry M, Heibein JA, Pinkoski MJ, Lee SF, Moyer RW, Green DR et al. Granzyme B shortcircuits the need for caspase 8 activity during granule-mediated cytotoxic T-lymphocyte killing by directly cleaving Bid. Mol Cell Biol 2000; 20: 3781-3794.
16. Waterhouse NJ, Sedelies KA, Trapani JA. Role of Bid-induced mitochondrial outer membrane permeabilization in granzyme B-induced apoptosis. Immunol Cell Biol 2006; 84: 72-78.

17. Metkar SS, Wang B, Ebbs ML, Kim JH, Lee YJ, Raja SM et al. Granzyme B activates procaspase-3 which signals a mitochondrial amplification loop for maximal apoptosis. $J$ Cell Biol 2003; 160: 875-885

18. Thomas DA, Scorrano L, Putcha GV, Korsmeyer SJ, Ley TJ. Granzyme B can cause mitochondrial depolarization and cell death in the absence of BID, BAX, and BAK. Proc Natl Acad Sci USA 2001; 98: 14985-14990.

19. Casciola-Rosen L, Garcia-Calvo M, Bull HG, Becker JW, Hines T, Thornberry NA et al. Mouse and human granzyme $B$ have distinct tetrapeptide specificities and abilities to recruit the bid pathway. J Biol Chem 2007; 282: 4545-4552.

20. Cullen SP, Adrain C, Luthi AU, Duriez PJ, Martin SJ. Human and murine granzyme B exhibit divergent substrate preferences. J Cell Biol 2007; 176: 435-444.

21. Kaiserman D, Bird CH, Sun J, Matthews A, Ung K, Whisstock JC et al. The major human and mouse granzymes are structurally and functionally divergent. J Cell Biol 2006; 175 : 619-630.

22. Waterhouse NJ, Sedelies KA, Browne KA, Wowk ME, Newbold A, Sutton VR et al. A central role for Bid in granzyme B-induced apoptosis. J Biol Chem 2005; 280: 4476-4482.

23. Godal R, Keilholz U, Uharek L, Letsch A, Asemissen AM, Busse A et al. Lymphomas are sensitive to perforin-dependent cytotoxic pathways despite expression of $\mathrm{PI}-9$ and overexpression of bcl-2. Blood 2006; 107: 3205-3211.

24. Sutton VR, Vaux DL, Trapani JA. Bcl-2 prevents apoptosis induced by perforin and granzyme B, but not that mediated by whole cytotoxic lymphocytes. J Immunol 1997; 158: 5783-5790.

25. Waterhouse NJ, Sutton VR, Sedelies KA, Ciccone A, Jenkins M, Turner SJ et al. Cytotoxic T lymphocyte-induced killing in the absence of granzymes $A$ and $B$ is unique and distinct from both apoptosis and perforin-dependent lysis. J Cell Biol 2006; 173: 133-144.

26. Willoughby CA, Bull HG, Garcia-Calvo M, Jiang J, Chapman KT, Thornberry NA. Discovery of potent, selective human granzyme $B$ inhibitors that inhibit CTL mediated apoptosis. Bioorg Med Chem Lett 2002; 12: 2197-2200.

27. Martin SJ, Finucane DM, Amarante-Mendes GP, O'Brien GA, Green DR. Phosphatidylserine externalization during CD95-induced apoptosis of cells and cytoplasts requires ICE/CED-3 protease activity. J Biol Chem 1996; 271: 28753-28756.

28. Schotte P, Declercq W, Van Huffel S, Vandenabeele P, Beyaert R. Non-specific effects of methyl ketone peptide inhibitors of caspases. FEBS letters 1999; 442: 117-121.

29. Schotte P, Schauvliege R, Janssens S, Beyaert R. The cathepsin B inhibitor Z-FA.fmk inhibits cytokine production in macrophages stimulated by lipopolysaccharide. J Biol Chem 2001; 276: 21153-21157.

30. Waterhouse NJ, Finucane DM, Green DR, Elce JS, Kumar S, Alnemri ES et al. Calpain activation is upstream of caspases in radiation-induced apoptosis. Cell Death Differ 1998; 5: 1051-1061.

31. Goldstein JC, Waterhouse NJ, Juin P, Evan Gl, Green DR. The coordinate release of cytochrome $c$ during apoptosis is rapid, complete and kinetically invariant. Nat Cell Biol 2000; 2: 156-162.

32. Davis JE, Smyth MJ, Trapani JA. Granzyme A and B-deficient killer lymphocytes are defective in eliciting DNA fragmentation but retain potent in vivo anti-tumor capacity. Eur J Immunol 2001; 31: 39-47.

33. Heusel JW, Wesselschmidt RL, Shresta S, Russell JH, Ley TJ. Cytotoxic lymphocytes require granzyme $\mathrm{B}$ for the rapid induction of DNA fragmentation and apoptosis in allogeneic target cells. Cell 1994; 76: 977-987.

34. Sarin A, Williams MS, Alexander-Miller MA, Berzofsky JA, Zacharchuk CM, Henkart PA Target cell lysis by CTL granule exocytosis is independent of ICE/Ced-3 family proteases. Immunity 1997; 6: 209-215.

35. Simon MM, Hausmann M, Tran T, Ebnet K, Tschopp J, ThaHla R et al. In vitro- and ex vivo-derived cytolytic leukocytes from granzyme $A \times B$ double knockout mice are defective in granule-mediated apoptosis but not lysis of target cells. J Exp Med 1997; 186: 1781-1786.

36. Jenkins MR, Kedzierska K, Doherty PC, Turner SJ. Heterogeneity of effector phenotype for acute phase and memory influenza A virus-specific CTL. J Immunol 2007; 179: 64-70.

37. Kelso A, Costelloe EO, Johnson BJ, Groves P, Buttigieg K, Fitzpatrick DR. The genes for perforin, granzymes A-C and IFN-gamma are differentially expressed in single CD8(+) T cells during primary activation. Int Immunol 2002; 14: 605-613.

38. Sun J, Bird CH, Buzza MS, McKee KE, Whisstock JC, Bird PI. Expression and purification of recombinant human granzyme B from Pichia pastoris. Biochem Biophys Res Commun 1999; 261: 251-255.

39. Sutton VR, Waterhouse NJ, Baran K, Browne K, Voskoboinik I, Trapani JA. Measuring cell death mediated by cytotoxic lymphocytes or their granule effector molecules. Methods 2008; doi:10.1016/j.ymeth.2007.11.011

40. Waterhouse NJ, Trapani JA. A new quantitative assay for cytochrome $c$ release in apoptotic cells. Cell Death Differ 2003; 10: 853-855. 